\title{
Specific feature of the restoration of operability of KPP-5 fasteners by using PRP-3.2 and PRP- 3.2.1 rail pads
}

\author{
Denis Fast $^{1, *}$, Natalia Bugaets ${ }^{1}$, Volodymir Vitolberg ${ }^{1}$, Alexandr Lichodey ${ }^{2}$, and Volodymyr \\ Stefanov ${ }^{1}$ \\ ${ }^{1}$ Ukrainian State University of Railway Transport, Feierbakh Square 7, 61050, Kharkiv, Ukraine \\ ${ }^{2}$ National Academy of the National Guard of Ukraine, Defenders of Ukraine Square 3, 61001, \\ Kharkiv, Ukraine
}

\begin{abstract}
Areas of rational use of the track construction with reinforced concrete sleepers have been defined, however, it requires improving and the problem of intermediate rail fastenings is particularly serious here. The most common intermediate rail fasteners used in Ukrzaliznytsya are lining terminal-bolted fasteners of $\mathrm{KB}$ type and direct fixation boltless fastening type KPP-5. Calculations have been made for the restoration of operability of KPP-5 fasteners using PRP-3.2 repair pads with a thickness of $9 \mathrm{~mm}$ and PRP-3.2.1 with a thickness of $10 \mathrm{~mm}$. It has been established that in the sections with the traffic load of more than 15 million ton $\mathrm{km} / \mathrm{km}$ in year, restoration works should be performed after 13 years of operation. Using $10 \mathrm{~mm}$ thick PRP-3.2.1 rail pads will provide the necessary pressing force of the rail base against the sleeper until the expiration of the standard service life - no more than 30 years. When the traffic load is less than or equal to 15 million ton $\mathrm{km} / \mathrm{km}$ in year, recovery can be performed after 22 years of operation. The use of both types of pads will ensure the reliable functioning of KPP-5 fasteners until the expiration of its service life.
\end{abstract}

\section{Introduction}

To date, the railway track construction with reinforced concrete sleepers is quite common for the Ukrainian railways. Areas of rational use of the track construction with reinforced concrete sleepers have been defined, however, it requires improving and the problem of intermediate rail fastenings is particularly serious here. The maintenance and repair works on intermediate rail fasteners take a significant proportion of labour input in the track operation. This is caused by many reasons [1-5], the main of which include the absence of clear scientifically rationalized mechanical, technological and operational parameters of the intermediate rail fasteners, which significantly affect the reliability of the railway track.

The most common intermediate rail fasteners used in Ukrzaliznytsya, which have undergone complete long-term operational observations, are lining terminal-bolted fasteners of KB type and direct fixation boltless fastening type KPP-5.

* Corresponding author: ppx_xiit@kart.edu.ua 
The main problems in the performance of these fasteners during operation can be determined based on the analysis of previous studies, the results of which are described in [6-10] devoted to the study of performance of KPP-5 fasteners and under conditions of nonpublic tracks:

1. The appearance of residual deformations in KPP-5 fastening elements due to wear of the rail pads, wear of the orifices in the anchoring beams, wear of the rail pads and the final deformation of the elastic terminals. This leads to a reduction in downforce of the rail base to the rail pad and, as a consequence, to violation of the normal temperature performance of the continuous welded track;

2. Changes in the stiffness of PRP-2.1 rail pads lead to the appearance of a spatial uneven stiffness of KPP-5 fasteners, which can lead to a significant increase in the spatial interaction forces between the track and the rolling stock, which in turn will increase the track defects.

PRP-3.2 and PRP-3.2.1 (A90 and A95) repair rail pads can compensate for these processes, but additional studies should be conducted in order to determine the rational areas of their application and their arrangement along the repaired section to ensure equal elasticity of the sub-rail base.

\section{The basic part}

To study the interaction dynamics of the rolling stock and the track in the vertical plane, it was convenient to use not absolute values of the interaction forces, but more convenient and informative dynamic coefficients. The dynamic coefficient is defined as the ratio of the value of dynamic forces $P_{d y n}$ to its statistical value $P_{s t}$

$$
K_{d y n}=P_{d y n} / P_{\text {st. }} \text {. }
$$

It should be noted that when the rails are used as beams on a solid elastic foundation in dynamic calculations of the vehicle and the track when the vehicle moves along a straight section at a constant speed, the dynamic coefficient is 1 . Meanwhile, under real conditions, vertical forces keep changing and this coefficient differs significantly from 1.

Fig. 1 shows the diagrams of the calculated changes in the vertical forces acting from the wheel to the rail when a 12-100 gondola car is moving along the track at a speed of $80 \mathrm{~km} / \mathrm{h}$. The distance travelled by the car is used as the abscissa, while the action force $P$ is the ordinate axis. In this example, the spatial stiffness of the rail supports was assumed to be constant.

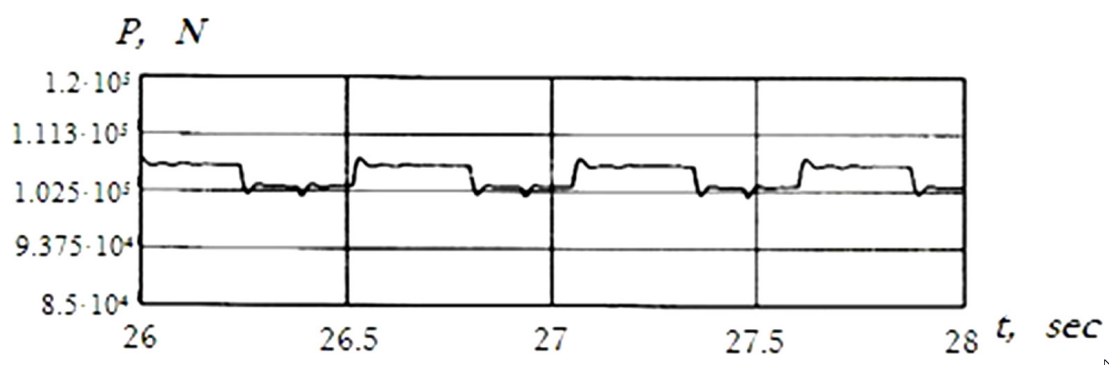

Fig. 1. Diagrams of dynamic vertical forces during the movement of a 12-100 gondola car

Introduction to the calculation of uneven elasticity of rail supports using the Monte Carlo method makes a very significant effect on the coefficients of dynamics. Diagrams of the dependence of changes in the dynamic coefficients on the uneven elasticity of the under-rail base with KPP-5 fasteners for PRP-2.1 rail pads for different service lives are shown in Fig. 2. 


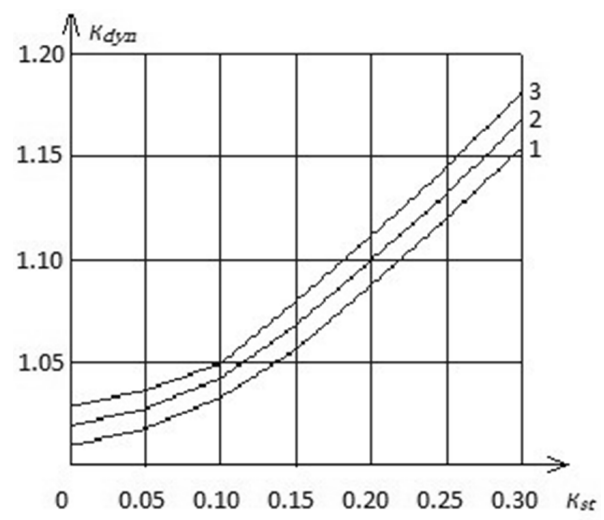

Fig. 2. Diagrams of dependence of the dynamics coefficients on the coefficients of the uneven elasticity of the under-rail base with KPP-5 fasteners and PRP-2.1 rail pads: 1 - service life 0 years; 2 - service life 13 years; 3 - service life 22 years

Further studies of the stress-strain state of rail track elements with SB-3-0 sleepers and KPP-5 fasteners [11] showed that the coefficient of uneven elasticity of the sub-rail base not exceeding 0.05 is permissible.

Table 1 shows the calculated values of the vertical stiffness of KPP-5 fasteners for various rail pads and their service life. The data were obtained from previous studies.

Table 1. Vertical stiffness of KPP-5 fasteners depending on service life and types of rail pads

\begin{tabular}{|c|c|c|c|c|c|c|}
\hline \multirow{2}{*}{ Years } & \multicolumn{7}{|c|}{ Types of rail pads } \\
\cline { 2 - 7 } & PRP-2.1 & PRP-2.11 & $\begin{array}{c}\text { PRP-3.2 } \\
(9 \mathrm{~mm} \mathrm{A90})\end{array}$ & $\begin{array}{c}\text { PRP-3.2 } \\
(9 \mathrm{~mm} \text { A95 })\end{array}$ & $\begin{array}{c}\text { PRP-3.2.1 } \\
(10 \mathrm{~mm} \text { A90) }\end{array}$ & $\begin{array}{c}\text { PRP-3.2.1 } \\
(10 \mathrm{~mm} \text { A95) }\end{array}$ \\
\hline 0 & 91.5 & 127.6 & 135.9 & 166.6 & 129.6 & 160.1 \\
\hline 5 & 105 & 141.1 & 149.4 & 180.1 & 143.1 & 173.6 \\
\hline 8.3 & 113.91 & 150.01 & 158.31 & 189.01 & 152.01 & 182.51 \\
\hline 10 & 118.5 & 154.6 & 162.9 & 193.6 & 156.6 & 187.1 \\
\hline 11.1 & 121.47 & 157.57 & 165.87 & 196.57 & 159.57 & 190.07 \\
\hline 12.7 & 125.79 & 161.89 & 170.19 & 200.89 & 163.89 & 194.39 \\
\hline 14.7 & 131.19 & 167.29 & 175.59 & 206.29 & 169.29 & 199.79 \\
\hline 15 & 132 & 168.1 & 176.4 & 207.1 & 170.1 & 200.6 \\
\hline 20 & 145.5 & 181.6 & 189.9 & 220.6 & 183.6 & 214.1 \\
\hline 25 & 159 & 195.1 & 203.4 & 234.1 & 197.1 & 227.6 \\
\hline 30 & 172.5 & 208.6 & 216.9 & 247.6 & 210.6 & 241.1 \\
\hline
\end{tabular}

The results of previous studies enable to make a conclusion that the restoration of operability of KPP-5 fasteners is possible using PRP-3.2 rail pads with a thickness of $9 \mathrm{~mm}$ and PRP-3.2.1 with a thickness of $10 \mathrm{~mm}$. Table 2 contains the calculated values of the stiffness gradients of fasteners and the coefficients of the uneven elasticity of the under-rail base are given after performing restoration.

Options of restoration section at which PRP-2.1 and PRP-2.11 rail pads were operated were considered. PRP-3.2 with a thickness of $9 \mathrm{~mm}$ and PRP-3.2.1 with a thickness of 10 $\mathrm{mm}$ was considered as rail pads being installed for recovery. Taking into account the earlier conclusion that the maximum permissible coefficient of the uneven elasticity of the underrail base should be 0.05 , the options with this and lower values do not require the formation of any transitional sections.

Also, in our opinion, the options of the restoration of operability of a fastener, in which the coefficient of uneven elasticity of the sub-rail base exceeds 0.25 , are inadmissible. For this reason, they were excluded from further calculations. 
Table 2. Stiffness gradients of KPP-5 intermediate rail fasteners and coefficients of uneven elasticity of the under-rail base when rail pads are replaced

\begin{tabular}{|c|c|c|c|c|c|c|c|}
\hline \multirow{2}{*}{$\begin{array}{l}\text { Traffic load, } \\
\text { million } \\
\text { ton } \cdot \mathrm{km} / \mathrm{km} \text { in } \\
\text { year }\end{array}$} & \multirow{2}{*}{$\begin{array}{l}\text { Term } \\
\text { replacement } \\
\text { of pads, } \\
\text { years }\end{array}$} & \multirow[t]{2}{*}{\begin{tabular}{|c|} 
Types of \\
pads until \\
replacement
\end{tabular}} & \multirow{2}{*}{$\begin{array}{l}\text { Stiffness of } \\
\text { fastener at the } \\
\text { moment of } \\
\text { replacement, } \\
\mathrm{kN} / \mathrm{mm}\end{array}$} & \multicolumn{4}{|c|}{$\begin{array}{l}\text { Stiffness gradient when repair rail } \\
\text { pads are replaced } \\
\frac{\Delta C_{y} k N / m m}{K_{u n, e l}}\end{array}$} \\
\hline & & & & $\begin{array}{c}9 \mathrm{~mm} \\
\mathrm{~A} 90\end{array}$ & $\begin{array}{c}9 \mathrm{~mm} \\
\mathrm{~A} 95\end{array}$ & $\begin{array}{c}10 \mathrm{~mm} \\
\mathrm{~A} 90\end{array}$ & $\begin{array}{c}10 \mathrm{~mm} \\
\mathrm{~A} 95\end{array}$ \\
\hline \multirow{2}{*}{$\leq 15$} & 22 & PRP-2.1 & 126.6 & $\frac{9.3}{0.07}$ & $\frac{40}{0.32}$ & $\underline{3.0}$ & $\frac{33.5}{0.26}$ \\
\hline & 22 & PRP-2.11 & 162.7 & $\frac{-26.8}{0.16}$ & $\frac{3.9}{0.02}$ & $\frac{-33.1}{0.2}$ & $\frac{-2.6}{-0.02}$ \\
\hline \multirow{2}{*}{$>15$} & 13 & PRP-2.1 & 150.36 & $\frac{-14.5}{0.1}$ & $\frac{16.2}{0.11}$ & $\frac{-20.8}{0.14}$ & $\frac{9.7}{0.06}$ \\
\hline & 13 & PRP-2.11 & 186.46 & $\frac{-50.6}{0.27}$ & $\frac{-19.9}{0.11}$ & $\frac{-56.9}{0.31}$ & $\frac{-26.4}{0.14}$ \\
\hline
\end{tabular}

Other options, depending on the values of the coefficient of uneven elasticity, were divided into four groups, depending on the values of this coefficient, see Table 3 .

Table 3. Options for restoration of operability of KPP-5 intermediate fastener

\begin{tabular}{|c|c|c|c|c|c|c|c|}
\hline $\begin{array}{l}\text { â } \\
\text { ڤै }\end{array}$ & $\begin{array}{l}\text { Types of } \\
\text { rail pads } \\
\text { until } \\
\text { restoration }\end{array}$ & $\begin{array}{l}\text { Stiffness of } \\
\text { fastener until } \\
\text { restoration, } \\
\mathrm{kN} / \mathrm{mm}\end{array}$ & $\begin{array}{c}\text { Traffic } \\
\text { load, } \\
\text { million } \\
\text { ton } \cdot \mathrm{km} / \mathrm{km} \\
\text { in year }\end{array}$ & $\begin{array}{c}\text { Types of } \\
\text { repair rail } \\
\text { pads at } \\
\text { replacement }\end{array}$ & $\begin{array}{l}\text { Stiffness of } \\
\text { fastener after } \\
\text { restoration, } \\
\mathrm{kN} / \mathrm{mm}\end{array}$ & $\begin{array}{c}\begin{array}{c}\text { Stiffness } \\
\text { gradient and } \\
\text { uneven } \\
\text { elasticity, }\end{array} \\
\frac{\Delta C_{y} k N / m m}{K_{u n, e l}}\end{array}$ & $\begin{array}{c}\text { Term } \\
\text { replacement } \\
\text { of rail pads, } \\
\text { years }\end{array}$ \\
\hline 1 & PRP-2.1 & 126.6 & $\leq 15$ & $\begin{array}{c}\text { PRP-3.2 } \\
9 \mathrm{~mm} \mathrm{A90}\end{array}$ & 135.9 & $\frac{9.3}{0.07}$ & 22 \\
\hline 2 & PRP-2.11 & 186.46 & $>15$ & $\begin{array}{c}\text { PRP-3.2 } \\
9 \text { mm A95 }\end{array}$ & 166.6 & $\frac{-19.9}{0.11}$ & 13 \\
\hline \multirow{2}{*}{3} & PRP-2.1 & 150.36 & \multirow{2}{*}{$>15$} & $\begin{array}{c}\text { PRP-3.2.1 } \\
10 \mathrm{~mm} \text { A90 }\end{array}$ & 129.6 & $\frac{-20.8}{0.14}$ & 13 \\
\hline & PRP-2.11 & 186.45 & & $\begin{array}{c}\text { PRP-3.2.1 } \\
10 \mathrm{~mm} \text { A95 }\end{array}$ & 160.1 & $\frac{-26.4}{0.14}$ & 13 \\
\hline 4 & PRP-2.11 & 162.7 & $\leq 15$ & $\begin{array}{c}\text { PRP-3.2.1 } \\
10 \mathrm{~mm} \mathrm{A90}\end{array}$ & 129.6 & $\frac{-33.1}{0.2}$ & 22 \\
\hline
\end{tabular}

Four such options were accepted:

Option 1 - coefficient of uneven elasticity within $>0.05 \div 0.09$;

Option 2 - coefficient of uneven elasticity within $\geq 0.10 \div 0.13$;

Option 3 - coefficient of uneven elasticity within $\geq 0.14 \div 0.16$;

Option 4 - coefficient of uneven elasticity more than 0.16 .

For these options, the pad arrangement schemes and the length of the transition sections to the recovery section were calculated using the software package of the dynamic "vehicletrack" system. The main criterion that was used as a basis for calculations is not exceeding the changes in stiffness of the under-rail base, at which the coefficient of uneven elasticity is 0.03 . At such values, additional dynamic forces in the transition sections will not exceed $4 \%$ of the static values of the wheel loads. 


\section{Conclusions}

The results of the studies suggest the following conclusions:

1. Calculations have been made for the restoration of operability of KPP-5 fasteners using PRP-3.2 repair rail pads with a thickness of $9 \mathrm{~mm}$ and PRP-3.2.1 with a thickness of $10 \mathrm{~mm}$. It has been established that in sections with the traffic load of more than 15 million ton $\mathrm{km} / \mathrm{km}$ in year, restoration works should be performed after 13 years of operation. Using $10 \mathrm{~mm}$ thick PRP-3.2.1 rail pads will provide the necessary pressing force of the rail base against the sleeper until the expiration of the standard service life - no more than 30 years. Use PRP-3.2 rail pads with a thickness of $9 \mathrm{~mm}$ will extent the operability for 10 years, then operability restoration works will be required again. Therefore, this option should be considered inappropriate. When the traffic load is less than or equal to 15 million ton $\mathrm{km} / \mathrm{km}$ in year, recovery can be performed after 22 years of operation. The use of both types of pads will ensure the reliable functioning of the KPP-5 fasteners until the expiration of its service life.

2. The results of the study of the influence of the uneven elasticity of the under-rail base on the dynamic interaction forces of the track and the rolling stock are given. The studies were conducted using the software package of the spatial dynamic "vehicle-track" system which was developed at the Department "Track and Track Facilities" of UkrSURT. It has been established that the uneven elasticity of the under-rail base of 0.05 should be considered permissible. In case of such values, the values of the additional dynamic forces will not exceed 1.035 .

3. Possible options for performing restoration work using PRP-3.2 rail pads with a thickness of $9 \mathrm{~mm}$ thick and PRP-3.2.1 with a thickness of $10 \mathrm{~mm}$ (A90, A95) at the sections where PRP-2.1 rail pads were inserted in the track have been considered. The stiffness gradients and the coefficients of the uneven elasticity of the sub-rail base have been calculated. In addition, the replacement of PRP-2.1 pads with either PRM-3.2 pads with a thickness of $9 \mathrm{~mm}$ thick (A95) or PRP-3.2.1 pads with a thickness of $10 \mathrm{~mm}$ (A95) if a traffic load is up to 15 million ton $\cdot \mathrm{km} / \mathrm{km}$ in year, as well as replacement of PRP-2.11 pads with PRP-3.2 pads with a thickness of $9 \mathrm{~mm}$ (A90) or PRP-3.2.1 pads with a thickness of $10 \mathrm{~mm}$ (A90) if a traffic load exceeds 15 million ton $\mathrm{km} / \mathrm{km}$ in year is impermissible.

4. Four schemes of the arrangement of transition sections were adopted depending on the coefficient of uneven elasticity of the under-rail base for other options for the restoration of operability of KPP-5 fasteners. The procedure of laying rail pads and the length of transitional sections have been calculated.

\section{References}

1. E.I. Danilenko, Railway Track. Arrangement, designing and calculations, interaction with the rolling stock (Kyiv, 2010)

2. V.V. Govorukha, Geotechnical mechanics, 31, 78-94 (2002)

3. A.N. Darenskiy, Zb. nauk. prats' UkrDAZT, 113, 171-177 (2010)

4. I. A. Ivanov, I.V. Amelichev, Sb. nauch. trudov VNIIGT. «Application of reinforced concrete in the upper track structure», 118, 56-59 (1984)

5. V.M. Tverdomed, Zb. nauk. prats' KUETT, 1-2, 36-41 (2003)

6. V.V. Govorukha Mechanics of deformation and destruction of elastic elements of intermediate rail fasteners (Dnipropetrovsk, 2005)

7. F. Rezaie, M.R. Shiri, S.M. Farnam, Engineering Failure Analysis, 26, 21-30 (2012) 
8. V.V. Ribkin, I.O. Bondarenko, R.V. Markul, Praci Mignar. nauk.-tech. conf. «Problems of the interaction of the track and rolling stock» DNUZT, 39 (2013)

9. V.G. Vitolberg, Forecasting of the service life of reinforced concrete sleepers SB 3-0 in conditions of non-public railways (Kyiv, 2013)

10. A.M. Darenskiy, V.G. Vitolberg, D.A. Fast, A.V. Klymenko, Y.S. Leibuk, MATEC Web of Conferences, 116, 03002 (2017)

11. N.I. Karpushchenko, N.I. Antonov, Improvement of rail fasteners (Novosibirsk, 2003) 